\title{
A COMPARATIVE STUDY OF EFFICACY AND SAFETY OF ULTRASOUND-GUIDED TRANSVERSUS ABDOMINIS PLANE (TAP) BLOCK WITH UNILATERAL SPINAL ANAESTHESIA FOR INGUINAL HERNIA REPAIR IN GERIATRIC PATIENTS
}

\author{
${ }^{1}$ Assistant Professor, Department of Anaesthesia, BRD Medical College, Gorakhpur, Uttar Pradesh. \\ ${ }^{2}$ Associate Professor, Department of Anaesthesia, BRD Medical College, Gorakhpur, Uttar Pradesh. \\ 3 Professor and HOD, Department of Anaesthesia, BRD Medical College, Gorakhpur, Uttar Pradesh. \\ ${ }^{4}$ Senior Resident, Department of Anaesthesia, BRD Medical College, Gorakhpur, Uttar Pradesh. \\ ${ }_{5}^{5}$ Assistant Professor, Department of Anaesthesia, BRD Medical College, Gorakhpur, Uttar Pradesh. \\ ${ }^{6}$ Professor, Department of Anaesthesia, BRD Medical College, Gorakhpur, Uttar Pradesh. \\ ${ }^{7}$ Assistant Professor, Department of Anaesthesia, BRD Medical College, Gorakhpur, Uttar Pradesh.
}

Santosh Kumar Sharma1, Shahbaz Ahmad², Satish Kumar 3 , Parvez Arshad Khan', Priyanka Dwivedi', Raka Rani', Narendra Deo ${ }^{7}$

\section{ABSTRACT}

\section{BACKGROUND}

Inguinal hernia repair, a commonly performed surgery in geriatric population is conducted under either general or regional anaesthesia. Post-operative pain in addition to poor cardiovascular and respiratory reserve in geriatric patients increases morbidity and length of hospital stay. Intravenous analgesics for postoperative pain produces various side effects. The unilateral spinal anaesthesia, which restricted the undesired sympathetic block is compared with ultrasound-guided (USG) transversus abdominis plane (TAP) block.

\section{MATERIALS AND METHODS}

Forty adult male geriatric patients of more than 60 years of age of ASA Grade I and II were divided into two groups of 20 each. They were given either USG TAP block (Group T) or unilateral spinal anaesthesia (Group S) for inguinal hernia repair surgery. Time to perform block, peak of block, quality of motor block, rescue analgesia for postoperative pain and side effects were noted. Statistical analysis was done by paired and unpaired " $t$ " test using SPSS version 16.0.

\section{RESULTS}

The time needed to perform block and time to reach maximum level of sensory block was significantly greater in Group T. The time taken for first rescue analgesia was significantly greater in Group T. The quality of block was better in Group S. No side effects were observed in Group T, while one patient had bradycardia and two patients had hypotension in Group S.

\section{CONCLUSION}

Unilateral spinal block provides better intra-operative block, while TAP block provides better postoperative analgesia with less haemodynamic disturbances and other side effects and may be used as sole anaesthetic technique in geriatric patients.

\section{KEYWORDS}

Geriatric Patients, Inguinal Hernia Repair Surgery, Unilateral Spinal Anaesthesia, Ultrasound-Guided Transversus Abdominis Plane Block.

HOW TO CITE THIS ARTICLE: Sharma SK, Ahmad S, Kumar S, et al. A comparative study of efficacy and safety of ultrasound-guided transversus abdominis plane (TAP) block with unilateral spinal anaesthesia for inguinal hernia repair in geriatric patients. J. Evolution Med. Dent. Sci. 2016;5(100):7356-7360, DOI: 10.14260/jemds/2016/1665

\section{BACKGROUND}

Inguinal hernia repair surgery is one of the commonest day care performed surgery in male geriatric patients with the incidence rising from 11 per 10,000 person-years aged 16 - 24 years to 200 per 10,000 person-years aged 75 years or above.(1)

These procedures can be done under General Anaesthesia (GA), neuraxial anaesthesia (spinal or epidural) or peripheral nerve blocks and TAP block. Geriatric patients have poor cardiovascular and respiratory reserves, hence general anaesthesia may not be a good option.

Financial or Other, Competing Interest: None.

Submission 25-10-2016, Peer Review 04-12-2016,

Acceptance 10-12-2016, Published 15-12-2016.

Corresponding Author:

Dr. Santosh Kumar Sharma,

Type 4/3, BRD Medical College Campus,

Gorakhpur, Uttar Pradesh, India.

E-mail: santoshtata76@gmail.com

DOI: $10.14260 /$ jemds $/ 2016 / 1665$
Neuraxial anaesthesia in geriatric patients causes hypotension and other haemodynamic changes. These autonomic nervous system response is diminished with aging and sympathetic block with epidural anaesthesia cannot be controlled. Hypotension is the most frequent side effect of spinal anaesthesia occurring in more than $30 \%$ of patients. ${ }^{(2)}$ In conventional spinal anaesthesia, it is not possible to limit the accompanied sympathetic block that normally exceeds the sensory block by 2 - 6 segments. $(3,4)$ Ward et al(5) reported a decrease in mean arterial blood pressure of $21.3 \%$ of the baseline following spinal anaesthesia. The unilateral spinal anaesthesia has been claimed by many as an alternative technique to restrict the undesired sympathetic block ${ }^{(6)}$ and is useful in geriatric patients.

The Transversus Abdominis Plane Block (TAPB) is a relatively new regional anaesthesia technique that provides analgesia to the parietal peritoneum as well as the skin and muscles of the anterior abdominal wall.(7) It has a high margin of safety and is technically simple to perform, especially under ultrasound guidance. TAPB can preserve bladder and lower 
limb motor function, thereby assisting early mobilisation after surgery. First described just a decade ago, it has undergone several modifications which have highlighted its potential utility for an increasing array of surgical procedures. ${ }^{\left({ }^{8}\right)}$ Despite a relatively low risk of complications and a high success rate using modern techniques, TAP blocks remain underutilised.(9)

There is no study comparing the potential of TAP block with unilateral spinal anaesthesia. Hence, this study was undertaken to compare the safety and efficacy of TAP block and unilateral spinal anaesthesia for inguinal hernia repair surgery in geriatric patients.

\section{MATERIALS AND METHODS}

After the study protocol was approved by Institutional Ethics Committee, the retrospective observational comparative study was conducted in the Department of Anaesthesiology, BRD Medical College, Gorakhpur, U.P., India. Our study had 40 adult male patients of more than 60 years of age and of American Society of Anaesthesiologists (ASA) Grade I and II who had undergone unilateral fully reducible indirect inguinal hernia repair surgery with mesh repair. The patients included in the study were divided into two groups: patients who received Ultrasound-guided (USG) Transversus Abdominis Plane Block (TAPB) (Group T) $(n=20)$ and patients who received a Unilateral Spinal Anaesthesia (USA) (Group S) (n = 20).

Group - T patients received USG-guided TAPB with $25 \mathrm{~mL}$ of $0.5 \%$ isobaric bupivacaine on the side of hernia repair and Group - S patients received USA with $10 \mathrm{mg}(2 \mathrm{~mL}$ ) of $0.5 \%$ hyperbaric bupivacaine. The same anaesthesiologist performed all procedures in both groups. The demographic data concerning the patient's (age, height, weight), ASA grading were noted. Heart rate, non-invasive systolic, diastolic, mean blood pressure were recorded at 5 minutes intervals initially for 20 minutes, 30 minutes, 45 minutes, 60 minutes and post-surgery. The time needed to perform the block, time needed for maximum level of sensory block, maximum motor block, duration of surgery were also recorded. The Visual Analogue Scale (VAS), which was postoperatively requested from the patients and recorded 4 hourly intervals up to first 24 hours. The VAS scale is a numerical scale in which having no pain is coded as 0 and having the most extreme unbearable pain is coded as 10 . The time taken for first rescue analgesia postoperatively and total analgesic consumption in first 24 hours, quality of block and incidence of side effects (egbradycardia, hypotension, nausea, vomiting, headache, bowel perforation, bladder catheterisation, etc.) were noted. Hypotension (defined as decrease in systolic blood pressure greater than $20 \%$ from baseline) was treated with mephentermine $6 \mathrm{mg}$ IV bolus and was repeated if required. Bradycardia (Heart rate less than 60 beats per minute) was treated with $0.3-0.6 \mathrm{mg}$ of atropine IV bolus.

All patients were premedicated with intravenous midazolam $1 \mathrm{mg}$ and fentanyl $50 \mu \mathrm{g}$ in the operating room before commencing with the procedure. In Group - T, patients were placed in supine position on OT table. Under all aseptic precautions, the ultrasound-guided (SonoSite, Micromaxx) TAPB was given using the following technique: A linear ultrasound probe (Micromaxx L 38e/10-5 MHZ) was placed transversely on the abdomen between costal margin and iliac crest in the midaxillary line on the side to be blocked. The probe was then slided anteriorly or posteriorly and tilted as necessary in a cephalocaudal direction until a clear optimised image of the three lateral abdominal muscles (namely external oblique, internal oblique and transversus abdominis from outside inwards) and the transversus abdominis plane were visualised. An 18-G Tuohy needle was introduced from an anteromedial position to a posterior and lateral direction using in-plane technique with entry point in the skin being 2 $\mathrm{cm}$ away from the probe in order to improve needle visibility in the long axis after skin infiltration with $1 \mathrm{~mL}$ xylocaine $1 \%$. A small test dose was used to confirm the transversus abdominis plane by observing the separation of fascia between internal oblique and transversus abdominis muscle. After confirming the transversus abdominis plane, a total of $25 \mathrm{~mL}$ of $0.5 \%$ isobaric bupivacaine was injected in real time. The block was assessed by pin prick on the side of surgery every 5 minutes till 30 minutes. A successful block meant a sensory block of unilateral T10 to L1 dermatomes by 30 minutes, after which it was considered as a failure and patient was given GA. In Group $S$ the unilateral spinal block was applied as follows: First, the extremity to be operated on was placed in the lateral decubitus position. After taking aseptic precautions, the subarachnoid space was entered in midline with a 25-gauge Quincke's needle from the L3 - L4 intervertebral space. After dural puncture, bevel of the needle was turned towards the dependent side and $2 \mathrm{~mL}(10 \mathrm{mg}$ ) of $0.5 \%$ hyperbaric bupivacaine was injected. Lateral position was maintained for 10 minutes and then patients were turned to supine position. The pin prick method was used to evaluate sensory block. Time of onset and time taken to achieve highest dermatomal level of sensory block was recorded. Motor blockade was assessed by using modified Bromage scale at the end of surgery. Patients with inadequate block in Group S were also converted to GA.

\section{The Quality of Block was Assessed according to the following Scale}

Numeric Scale for Quality of Block.

Grade IV - (Excellent) No complaint from patient.

Grade III - (Good) Minor complaint with no need for the supplemental analgesics.

Grade II - (Moderate) Complaint that required supplemental analgesia.

Grade I - (Unsuccessful) Patient given general anaesthesia. Motor blockade was assessed by using modified Bromage scale.

Grade 0 - No block.

Grade 1 - Inability to raise the extended legs.

Grade 2 - Inability to flex knee.

Grade 3 - Inability to flex ankle and foot.

Intermittent bolus of 25 - 50 mcg of fentanyl was given intravenously to patients who needed supplemental analgesics. Tramadol $50 \mathrm{mg}$ intravenous was used as a rescue analgesic in patients who had VAS score $\geq 4$ postoperatively. Both groups were analysed by student's ' $t$ ' test. For intragroup comparison, paired ' $t$ ' test was used and for intergroup comparison unpaired ' $\mathrm{t}$ ' test was used. Taking confidence interval $(\alpha=0.05)$ and power of test $(1-\beta)$ as $80 \%$, we used a sample size of total 40 patients (20 in each group). For all statistical analysis, the value of $\mathrm{p}<0.05$ was considered statistically significant and value of $p<0.001$ was considered highly significant. All statistical tests were done using SPSS 
software version 16.0. Graphs were prepared using Microsoft Excel. Data was expressed as mean \pm standard deviation.

\section{RESULTS}

The baseline demographic parameters were statistically comparable in both groups (Table 1). The intraoperative haemodynamic parameters were comparable regarding Heart Rate (HR), but SBP, DBP and MBP were significantly reduced in Group S (Figure 1). Two patients had hypotension and one patient had Bradycardia in Group S, while no complications were seen in Group T. The time needed to perform block and time needed for maximum level of sensory block were significantly more in Group T. There was significantly lower VAS scores in Group T (Figure 2) and the duration of postoperative analgesia was significantly higher in Group T (Table 2). The total dose of rescue analgesic required in Group T was significantly less (Table 2). The total fentanyl consumption was higher in Group T. A significantly higher number of patients in Group T had lower Bromage scores (Table 2).

\begin{tabular}{|c|c|c|c|c|}
\hline & Group T & Group S & P value & Significance \\
\hline & Mean \pm SD & Mean \pm SD & $>0.5$ & NS \\
\hline Age (Years) & $67.4 \pm 4.2$ & $69.15 \pm 6.14$ & $>0.5$ & $\mathrm{NS}$ \\
\hline Height (CM) & $166.0 \pm 3.42$ & $165.8 \pm 3.42$ & $>0.5$ & $\mathrm{NS}$ \\
\hline Weight (KG) & $63.45 \pm 5.13$ & $65.5 \pm 6.86$ & $>0.5$ & $\mathrm{NS}$ \\
\hline ASA Grade (I/II) & $14 / 6$ & $12 / 8$ & $>0.5$ & $\mathrm{NS}$ \\
\hline Duration of Surgery (Min) & $61.82 \pm 7.20$ & $60.82 \pm 6.59$ & $>0.5$ & $\mathrm{NS}$ \\
\hline Table 1. Distribution of Patients According to their Demographic Data and Other Baseline Parameters
\end{tabular}

\begin{tabular}{|c|c|c|c|c|}
\hline Parameters & $\begin{array}{l}\text { Group T } \\
(N=20)\end{array}$ & $\begin{array}{l}\text { Group } S \\
(\mathrm{~N}=20)\end{array}$ & $\begin{array}{c}\mathbf{p} \\
\text { Value }\end{array}$ & Significance \\
\hline $\begin{array}{c}\text { Time } \\
\text { Needed to } \\
\text { Perform } \\
\text { Block (mins.) }\end{array}$ & $23.75 \pm 3.58$ & $8.80 \pm 2.60$ & $<0.001$ & $S$ \\
\hline $\begin{array}{c}\text { Time } \\
\text { Needed } \\
\text { for } \\
\text { Maximum } \\
\text { Level of } \\
\text { Sensory Block }\end{array}$ & $28.0 \pm 1.29$ & $6.68 \pm 0.74$ & $<0.001$ & S \\
\hline $\begin{array}{l}\text { Modified Bromage } \\
\text { Score }(3 / 2 / 1 / 0)\end{array}$ & $0 / 0 / 0 / 30$ & $6 / 9 / 5 / 0$ & $<0.001$ & S \\
\hline $\begin{array}{c}\text { Time Taken } \\
\text { for First } \\
\text { Analgesic Requirement } \\
\text { Postoperatively }\end{array}$ & $\begin{array}{c}941.0 \pm 235.68 \\
\text { (13 patients did not } \\
\text { require } \\
\text { rescue } \\
\text { analgesia) }\end{array}$ & $240.75 \pm 5.44$ & $<0.001$ & S \\
\hline $\begin{array}{l}\text { Total Rescue Analgesic } \\
\text { Requirement (Tramadol in mg) }\end{array}$ & $17.5 \pm 24.5$ & $110 \pm 20.5$ & $<0.001$ & $S$ \\
\hline $\begin{array}{c}\text { Total Fentanyl } \\
\text { used } \\
\text { in mcg } \\
\end{array}$ & $76.25 \pm 23.61$ & $50.0 \pm 0.0$ & $<0.001$ & $S$ \\
\hline Quality of Block (4/3/2/1) & $0 / 6 / 14 / 0$ & $19 / 1 / 0 / 0$ & $<0.001$ & $\mathrm{~S}$ \\
\hline Table 2. Compar & $\begin{array}{r}\text { ous Variables } R \epsilon \\
\text { between } G r\end{array}$ & $\begin{array}{l}\text { Block Charo } \\
\text { d Groups }\end{array}$ & d Usa & \\
\hline
\end{tabular}

\begin{tabular}{|c|c|c|}
\hline Side Effect/Complications & Group T & Group S \\
\hline Bradycardia & 0 & 1 \\
\hline Hypotension & 0 & 2 \\
\hline (Nausea/Vomiting) & 0 & 0 \\
\hline Headache & 0 & 0 \\
\hline LA Toxicity & 0 & 0 \\
\hline $\begin{array}{c}\text { Liver Perforation/ } \\
\text { Bowel Haematoma, } \\
\text { Intraperitoneal Injection) }\end{array}$ & 0 & 0 \\
\hline Urinary Catheterisation & 0 & 2 \\
\hline Table 3. Comparison of Side Effect/Complications in \\
Group T and Group S \\
\hline \multicolumn{2}{|c}{} \\
\hline \multicolumn{2}{|c|}{}
\end{tabular}

\begin{tabular}{|c|c|c|}
\hline Grade & Group T (\%) & Group S (\%) \\
\hline 4 & $0(0 \%)$ & $19(95.0 \%)$ \\
\hline 3 & $6(30.0 \%)$ & $1(5.0 \%)$ \\
\hline 2 & $14(70.0 \%)$ & $0(0.0 \%)$ \\
\hline 1 & $0(0.0 \%)$ & $0(0.0 \%)$ \\
\hline \multicolumn{3}{|c|}{ Table 4. Quality of Block in Both Groups } \\
\hline
\end{tabular}

Grade 4 - Excellent Block.

Grade 3 - Good Block.

Grade 2 - Moderate Block.

Grade 1 - Failed Block, General Anaesthesia Given. 


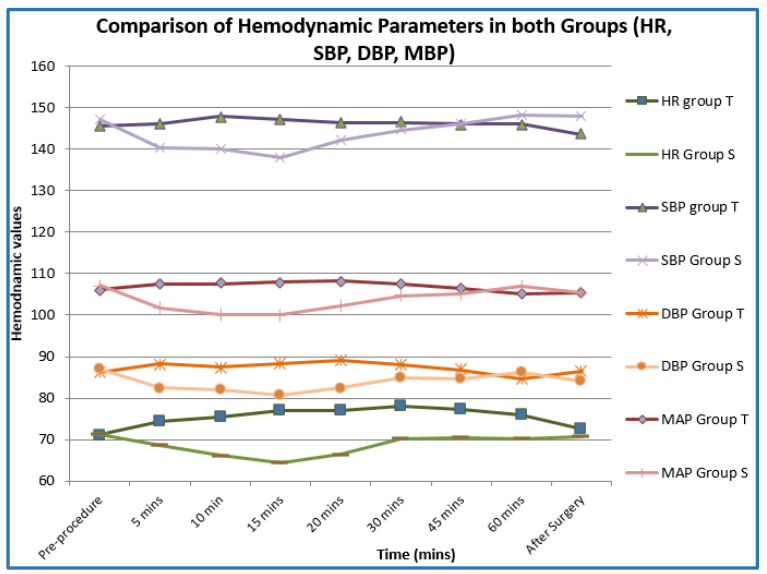

Figure 1. Comparison of Haemodynamic Parameters in Group $T$ and $S$

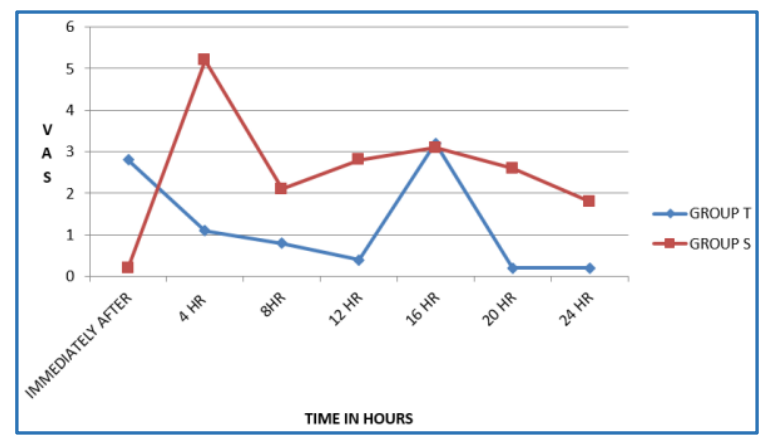

Figure 2. Mean VAS Score in First 24 Hours Post-Operatively in Both Groups

\section{DISCUSSION}

TAPB is a new rapidly expanding regional anaesthesia technique significantly reduces pain associated with lower abdominal surgery, regardless of whether it is used as primary anaesthetic or for pain relief postoperatively. USG has provided the required precision and safety to this truncal block.

Unilateral spinal anaesthesia using $0.5 \%$ bupivacaine is a standard and effective regional anaesthesia technique in restricting sympathetic block in all high risk patients including geriatric patients. Minimal haemodynamic changes following this technique is observed.

The demographic data of the patients in both groups (Table 1) were similar in age, mean height, weight and ASA grades. The duration of surgical procedure was also comparable in both groups.

The duration required to perform block (Table 2) was greater in Group T ( $23.75 \pm 3.58$ mins.) in comparison to Group $\mathrm{S}(8.8 \pm 2.60 \mathrm{mins}$.) and was found to be highly significant $(\mathrm{p}<$ $0.001)$.

The time to reach highest/maximum level of sensory block (Table 2) was higher in Group T ( $28 \pm 1.29$ mins.) as compared to Group S (6.68 \pm 0.74 mins.) and was found to be highly significant ( $p<0.001)$. Shibata et al (2007) assessed the extent of ultrasound-guided TAPB by pinprick in 26 patients undergoing laparoscopic gynaecological surgeries and found that the mean upper and lower level of sensory block at 30 mins. after local anaesthetic injection were T10 (Range, T9 11) and L1 (Range, T12 - L1) respectively,(10) which is comparable with our Group T i.e. $28 \pm 1.29$ mins. Nesek Adam et al (2011) conducted a prospective, randomised study to compare between unilateral and bilateral spinal anaesthesia in hypertensive patients undergoing surgery for varicose veins and found the mean time for peak onset of sensory block was $5.4 \pm 0.8$ mins. in their unilateral group as compared to $5.1 \pm$ 0.8 mins. in bilateral group.(11) In another study conducted by Manisha Sepate et al (2014) on evaluation of bupivacaineclonidine combination for unilateral spinal anaesthesia in lower limb below-knee orthopaedic surgery, the mean time for peak onset of sensory block was $4.7 \pm 1.23$ mins. in bupivacaine-clonidine combination group as compared to 6.27 \pm 1.51 mins. in group containing Bupivacaine alone.(12) In Group $S$ of our study, the time to reach the highest level of sensory block was $6.68 \pm 0.74$ mins., which was comparable to the above two studies.

There was no motor blockade in Group $\mathrm{T}$, whereas mean modified Bromage scale grade was $2.05 \pm 0.75$ in Group $S$ (Table 2), which was statistically significant ( $p<0.001)$. Zorica Jankovic et al (2009) in their study "transversus abdominis plane block in (lower) abdominal surgery" found that there are no motor deficiency in TAP block.(13) In the study of Nesek Adam et al (2011) found the mean modified Bromage scale was $2.5 \pm 0.6$ mins. in unilateral and $2.4 \pm 0.6$ mins. in bilateral group at 15 minutes of block, which is consistent with our study.(12)

In Group T, the heart rate were higher compared to their pre-procedure values at all time intervals measured (Figure 1). This rise in heart rate may be attributed to many factors like anxiety or inability to achieve excellent grade of block. In Group S, the heart rate was lower compared to their preprocedure value at all time interval measured. Heart rate then returned to pre-procedure values after 20 minutes.

In Group T there was no significant changes in the systolic, diastolic and mean blood pressures compared to their preprocedure values. In Group $\mathrm{S}$, there was a statistically significant fall in the systolic, diastolic and mean blood pressures after giving unilateral spinal block. Hypotension was noticed in $10 \%$ patients ( 2 out of 20 patients), that was treated with mephentermine IV bolus. Blood pressures returned to their pre-procedure values after 15 minutes. In the study of Sulagna Bhattacharjee et al (2014), systolic and diastolic BP were significantly higher in Group N (TAP block with normal saline followed by general anaesthesia) in comparison to Group B (TAP block with 0.25\% Bupivacaine followed by general anaesthesia).(14) K. O. Connor et al (2010) reported that there is no haemodynamic sequelae of neuraxial sympathectomy in TAP block as in neuraxial block.(15) The fall in SBP and DBP after unilateral spinal was similar to study by Casati et al (1999) in the unilateral spinal anaesthesia group using hyperbaric $0.5 \%$ bupivacaine. They noticed hypotension in $10 \%$ patients that were treated with $100 \mathrm{mcg}$ of phenylephrine.(16) Nesek Adam et al (2011) had also noticed slight decrease in blood pressure in their unilateral group. They also noticed hypotension in $10 \%$ patients.(12)

The duration of analgesia (the time taken for first rescue analgesic) (Table 2) was more in Group T ( $941 \pm 235.68$ mins.) as compared to Group S (240.75 \pm 5.44 mins); 13 patients in Group $\mathrm{T}$ did not require any rescue analgesia in first 24 hours (highly significant, $\mathrm{p}$ value $<0.001$ ). The mean VAS immediately after surgery was more in Group $\mathrm{T}(2.8 \pm 0.55)$ in comparison to Group S $(0.2 \pm 0.32)$ (Highly significant, $p<$ 0.001). The mean VAS afterwards was more in Group $S$ in comparison to Group $\mathrm{T}$. The finding of prolonged postoperative analgesia after USG TAPB is similar to studies by 
other authors. Iyad Abbas Salman et al (2012) have observed in their comparison between TAP block and parenteral analgesia post-caesarean section that traditional treatment had better pain control in $1^{\text {st }} 2$ hours, whereas TAP block was better thereafter.(17) Similarly, in the study of Isil Davarci et al the VAS score was $<1$ up to 90 minutes and increased gradually to $1,3,3$ at 2, 4 and 6 hours respectively and then decreased to 1.5 at 24 hours in their USA group.(18) In the study of Manisha Sepate et al (2014), the mean time for requirement of rescue analgesia was $220 \pm 36.36$ mins. in their control group (unilateral spinal anaesthesia with Bupivacaine alone).(13)

The quality of block (Table 4) was better in Group S in comparison to Group T. As TAP block have no effect on visceral pain, hence quality of block were poorer in TAP group. No patients $(0.0 \%)$ in Grade 4 (excellent) block, 6 patients $(30.0 \%)$ in Grade 3 (Good) block, 14 patients (70.0\%) in Grade 2 (Moderate) block and no patients $(0 \%)$ in Grade 1.

Comparing the side effects and complications in both groups, there were no side effects or complications in Group T. Karim Mukhtar et al (2009) stated that TAP block have high margin of safety, especially under ultrasound guidance. There have been no reported complication to date with the ultrasound-guided technique.(19) In Group S, 1 patient (5.0\%) presented with bradycardia and 2 patients $(10.0 \%)$ presented with hypotension. Limiting the spread of the spinal block by giving unilateral spinal greatly reduced the haemodynamic impact, which is due to compensation by a reflex vasoconstriction in the non-blocked areas. Clinical trials comparing unilateral spinal anaesthesia with conventional bilateral spinal block have demonstrated that cardiac index values are much more stable during USA with a smaller reduction in arterial blood pressure and heart rate and a much lower incidence of clinically relevant hypotension (5\% Vs 20\%) (Casati et al 1999).(17) TAP block thus provides better perioperative haemodynamic safety profile.

Regarding limitations of our study, one was the small sample size and hence future studies need to be undertaken with a large size population. Another limiting factor is that although USG TAPB increases efficiency and safety of block it has a longer learning curve and so results are user dependent. There are various techniques to perform TAP block, so it must be realised that the block characteristics can change with each technique. Complete blinding was not possible, which is another limitation of our study.

\section{CONCLUSION}

TAP block is more efficacious than unilateral spinal block for inguinal hernia repair in geriatric patients in terms of prolonged post-operative analgesia, excellent haemodynamic stability with minimal incidence of side effects or complications. On the other hand, unilateral spinal block provides excellent quality of intra-operative block. TAP block may be used safely as an alternative sole anaesthetic technique in geriatric patients who are not suitable for general or neuraxial anaesthesia.

\section{REFERENCES}

1. Jenkins JT, O'Dwyer PJ. Inguinal hernias. BMJ 2008;336(7638):269-72.

2. Carpenter RL, Caplan RA, Brown DL, et al. Incidence and risk factors for side effects of spinal anesthesia. Anesthesiology 1992;76(6):906-16.
3. Greene NM. The area of differential block during spinal anesthesia with hyperbaric tetracaine. Anesthesiology 1958;19(1):45-50.

4. Chamberlain DP, Chamberlain BDL. Changes in the skin temperature of the trunk and their relationship to sympathetic blockade during spinal anesthesia. Anesthesiology 1986;65(2):139-43.

5. Ward RJ, Bonica JJ, Frend PG, et al. Epidural and subarachnoid anesthesia cardiovascular and respiratory effects. J Am Mod Assoc 1965;191(4):275-8.

6. Casati A, Fanelli G, Beccaria P, et al. Block distribution and cardiovascular effects of unilateral spinal anesthesia by $0.5 \%$ hyperbaric bupivacaine. A clinical comparison with bilateral spinal block. Minerva Anesthesiology 1998;64(7-8):307-12.

7. Charlton S, Cyna AM, Middleton P, et al. Perioperative transversus abdominis plane (TAP) blocks for analgesia after abdominal surgery. Cochrane Database Systematic Reviews 2010;8(12):Art no. CD007705.

8. Rafi AN. Abdominal field block: a new approach via the lumbar triangle. Anaesthesia 2001;56(10):1024-6.

9. Kearns RJ, Young SJ. Transversus abdominis plane blocks: a national survey of techniques used by UK obstetric anaesthetists. International Journal of Obstetric Anesthesia 2011;20(1):103-4.

10. Yasuyuki S, Yuko S, Yoshihiro F, et al. Transversus abdominis plane block. Anesthesia \& Analgesia 2007;105(3):883.

11. Adam VN, Stojcic EG, Maldini B, et al. Bilateral vs. unilateral spinal anesthesia for varicose vein surgery in hypertensive patients. Periodicum Biologorum 2011;113(3):349-53.

12. Sapate M, Sahu P, Shah B, et al. Evaluation of bupivacaineclonidine combination for unilateral spinal anesthesia in lower limb below-knee orthopedic surgery. Saudi J Anaesth 2014;8(3):384-7.

13. Jankovic Z. Transversus abdominis plane block: the holy grail of anaesthesia for (lower) abdominal surgery. Periodicum Biologorum 2009;111(2):203-8.

14. Bhattacharjee $S$, Ray M, Ghose T, et al. Analgesic efficacy of transversus abdominis plane block in providing effective perioperative analgesia in patients undergoing total abdominal hysterectomy: a randomized controlled trial. J Anaesthesiol Clin Pharmacol 2014;30(3):391-6.

15. O'Connor K, Renfrew C. Subcostal transversus abdominis plane block. Anaesthesia 2010;65(1):91-2.

16. Casati A, Fanelli G, Aldegheri G, et al. Frequency of hypotension during conventional or asymmetric hyperbaric spinal block. Reg Anesth Pain Med 1999;24(3):214-9.

17. Salman IA, Kamel HS. A comparison between the transversus abdominis plane (TAP) block versus traditional parentral analgesia post caesarian section. The Iraqi Postgraduate Medical Journal 2012;11 Suppl.

18. Davarci I, Tuzcu K, Karcioglu M, et al. Comparison between ultrasound-guided sciatic-femoral nerve block and unilateral spinal anaesthesia for outpatient knee arthroscopy. Journal of International Medical Research 2013;41(5):1639-47.

19. Mukhtar K. Transversus abdominis plane (TAP) block. The Journal of New York School of Regional Anesthesia 2009;12:28-33. 